\title{
Establishment of specific cytotoxic T lymphocyte culture system and its inhibitory effect on ovarian cancer
}

\author{
MINGXING SUI, LIHUI SI, TIANMIN XU* and MANHUA CUI* \\ Department of Gynecology and Obstetrics, The Second Hospital of Jilin University, Changchun, Jilin 130041, P.R. China
}

Received April 24, 2015; Accepted September 2, 2016

DOI: $10.3892 / 01.2016 .5202$

\begin{abstract}
The present study aimed to establish a novel method for efficiently inducing cytotoxic T lymphocytes (CTLs) in vitro, in order to develop an immune-based therapy for suppressing and killing ovarian cancer cells with a high safety and efficacy. Peripheral blood mononuclear cells (PBMCs) were stimulated with $\mathrm{CpG}$ oligodeoxynucleotide (CpGODN) and ginsenoside $\mathrm{Rg} 1$, which were united as an immune adjuvant, and human epidermal growth factor receptor 2 (HER2/neu) antigen peptide, in order to establish a specific CTL culture system in vitro. Chromosome karyotype analysis, growth curve construction and flow cytometric analysis of immune phenotypes, including cluster of differentiation (CD)3, CD4 and CD8, were performed to characterize the stimulated PBMCs in vitro. Subsequently, SKOV3 ovarian cancer cells were treated with the specific CTL culture system in vitro, and MTT assays were performed to test the inhibitory and lethal effects of the CTLs on SKOV3 cells. The number of CTLs was significantly increased from day 7 of stimulation with the specific mixture (CpGODN, ginsenoside Rg1 and HER2/neu) $(\mathrm{P}<0.01)$, and plateaued on day 19. Following activation, the number of $\mathrm{CD}^{+}, \mathrm{CD}^{+}{ }^{+} \mathrm{CD} 4^{+}$and $\mathrm{CD}^{+} \mathrm{CD}^{+}$cells was significantly increased $(\mathrm{P}<0.01)$. The lymphocyte karyotype did not change following exposure to antigen. After treatment with the specific CTL system, the number of SKOV3 cells in the experimental group was significantly reduced compared with that in the control group $(\mathrm{P}<0.01)$. The results of the present study suggested that two novel immune adjuvants, CpGODN and ginsenoside Rg1, could be combined with the HER2/neu
\end{abstract}

Correspondence to: Professor Manhua Cui or Dr Tianmin Xu, Department of Gynecology and Obstetrics, The Second Hospital of Jilin University, 218 Ziqiang Road, Changchun, Jilin 130041, P.R. China

E-mail: cuimanhua55@126.com

E-mail: xutianmin@126.com

\section{${ }^{*}$ Contributed equally}

Key words: immune antigen, ovarian cancer, immunotherapy, $\mathrm{CpG}$ oligodeoxynucleotide, ginsenoside $\mathrm{Rg} 1$, human epidermal growth factor receptor $2 / \mathrm{neu}$, cytotoxic $\mathrm{T}$ lymphocyte antigen peptide to establish a specific CTL culture system in vitro. This system demonstrated a high antigen specificity, safety and proliferative ability, and exerted significant lethal and inhibitory effects on SKOV3 cells in vitro.

\section{Introduction}

Ovarian cancer is one of the most common gynecological malignant tumors with a high mortality rate; it remains the most common cause of gynecological cancer-associated mortality (1). Epithelial ovarian cancer (EOC) constitutes $>90 \%$ of ovarian malignancies (2), and is often found in the advanced stage of ovarian cancer (3). Although traditional tumor cytoreduction and platinum-based chemotherapy can relieve the disease, $\sim 70 \%$ of patients with advanced ovarian cancer relapse, and the majority succumb to severe side effects and chemotherapy resistance (4). The 5-year survival rate for ovarian cancer has not improved significantly over time, and it remains a serious threat to the lives and health of women (5).

In the last two decades, immunotherapy for EOC has emerged as an attractive auxiliary treatment method. It is commonly accepted that ovarian tumors are immunogenic (6). Previous studies have associated antitumor immune responses with a significant improvement in overall survival $(7,8)$, which may be due to their ability to increase antitumor immunological activity, thereby inhibiting and killing tumor cells. Among the various types of immunotherapy, adoptive cellular immunotherapy involving the infusion of immunocompetent cells with antitumor activity into patients in order to directly kill tumor cells or stimulate the body's immune response is one of the hotspots in cancer treatment $(9,10)$. An important issue of immunotherapy is the selection of appropriate tumor killing cells: Cytotoxic T lymphocytes (CTLs) are the first to respond to tumor antigens and the most effective of the effector cells in the killing of tumor cells (11). CTLs are able to eliminate minimal residual nidi and may even entirely attenuate advanced cancer; thus, they have an important role in antitumor immunotherapy $(11,12)$.

CTL activation requires a double-signal stimulus. Tumor antigen peptides are processed as polypeptides by antigen-presenting cells (APCs), combined with major histocompatibility complex (MHC) molecules and transported to the APC surface to generate a T-cell receptor (TCR) activation signal (13). The combination of antigen and relevant receptors on the surface of $\mathrm{T}$ lymphocytes generates the co-stimulatory 
signal, which is the second signal (14). Only upon stimulation with both the TCR activation signal and the co-stimulatory signal can T lymphocytes be activated (13). Adjuvants are able to non-specifically alter or enhance the body's specific immune response to antigens, enhance the immunogenicity of the corresponding antigen or change the type of immune response (15).

Human epidermal growth factor receptor 2 (HER2/neu) is an attractive immunological target, since HER2/neu activates signaling pathways involved in cellular differentiation, proliferation, migration and apoptosis (16). It has previously been demonstrated that HER2/neu is recurrently overexpressed in ovarian cancer, which may lead to enhanced cell proliferation and malignant phenotype transformation $(17,18)$. In addition, previous studies have reported that HER $2 /$ neu is an important surface biomarker of ovarian cancer cells and is associated with a poor prognosis and chemotherapy resistance (19-21). Oligodeoxynucleotides with CpG motifs (CpG oligodeoxynucleotide; CpGODN) have shown strong immune activation effects (22), adjuvant effects and a low toxicity; they are suitable for artificial synthesis and are one of the strongest novel adjuvants to date (23). Ginsenoside has previously shown a strong activity in the prevention and inhibition of the growth and metastasis of tumors (24). The ginsenoside Rg1 monomer is an effective immune adjuvant that can stimulate the proliferation of $\mathrm{T}$ and $\mathrm{B}$ lymphocytes and differentiation of antigen-specific lymphocytes $(25,26)$.

The present study aimed to establish a novel method for inducing large numbers of CTLs via the double-signal activation pathway, in order to develop an immune-based therapy for the inhibition and killing of ovarian cancer cells with a high safety and efficacy. CpGODN and ginsenoside Rg1 were united as an immune adjuvant and, combined with the HER2/neu antigen peptide, were used to establish a specific CTL culture system in vitro. Subseuqently, the inhibitory and lethal effects of the CTL culture system on SKOV3 ovarian cancer cells were assessed. The results of the present study may provide the experimental foundation for further research on the function and mechanism of CTLs in tumor immunotherapy, and provide a theoretical basis for their clinical promotion and application.

\section{Materials and methods}

Ethics statement. This study was performed in accordance with institutional and national guidelines and regulations, and with approval from the Ethics Committee of The Second Hospital of Jilin University (Changchun, China). Written informed consent was obtained from all patients.

Isolation of peripheral blood mononuclear cells (PBMCs) and cell culture. Peripheral blood $(20 \mathrm{ml})$ was obtained from healthy donors by venipuncture at The Second Hospital of Jilin University between June 2013 and December 2014, and PBMCs were isolated by density gradient centrifugation (27) using lymphocyte separation medium (Beijing Dingguo Biological Technology, Co., Ltd., Beijing, China). Cell counts of living cells were determined by trypan blue staining exclusion assays. The SKOV3 human ovarian cancer cell line was purchased from the Type Culture Collection of the Chinese Academy of Sciences (Shanghai, China). PBMCs and SKOV3 cells were cultured in RPMI-1640 medium (Gibco; Thermo Fisher Scientific, Inc., Waltham, MA, USA) containing 10\% fetal bovine serum (FBS; Hyclone; GE Healthcare Life Sciences, Logan, UT, USA) at $37^{\circ} \mathrm{C}$ in a humidified $5 \% \mathrm{CO}_{2}$ incubator. SKOV3 cells in the logarithmic growth phase were used in the study.

Specific antigen epitopes. CTL antigen epitopes were predicted using GenBank (https://www.ncbi.nlm. nih.gov/genbank/), CLC Protein Workbench 3 (CLC bio, Waltham, MA, USA) and the SignalP 3.0 server (http://www.cbs.dtu.dk/services/SignalP-3.0/). A 9-amino acid human leukocyte antigen-A2-restricted CTL epitope corresponding to a cleavage site of the HER2/neu tumor antigen was also predicted by the above mentioned software. Finally, the P369-377 peptide epitope, which has previously been shown to be immunocompetent (28-31), was elected as the antigen peptide from the antigen epitope prediction results. The amino acid sequence of the P369-377 peptide epitope was as follows: Lysine-isoleucine-phenylalanine (Phe)-glycine-serine-leucine (Leu)-alanine-Phe-Leu. The peptide was synthesized by Sangon Biotech, Co., Ltd. (Shanghai, China).

Viability of SKOV3 cells treated with PBMCs activated by various concentrations of stimulators. The concentration of PBMCs was adjusted to $1 \times 10^{6} / \mathrm{ml}$ and the cells were inoculated into 96-well plates (100 $\mu \mathrm{l} /$ well). HER2/neu antigen peptide (Sangon Biotech, Co., Ltd.) was added into five groups of CpGODN (Sangon Biotech Co., Ltd.) or ginsenoside Rg1 (purity >99\%; Jilin University) at different concentrations $(3.75,7.5,15,30$ or $60 \mu \mathrm{g} / \mathrm{ml})$, making the final concentration of HER2/neu $10 \mu \mathrm{g} / \mathrm{ml}$. Subsequently, the mixtures containing various concentrations of CpGODN or ginsenoside $\mathrm{Rg} 1$ were added to the PBMCs and incubated for 7 days; each group consisted of three parallel wells. SKOV3 cells in the logarithmic growth phase were digested with $0.25 \%$ trypsin and diluted in RPMI-1640 medium containing 10\% FBS. The single cell suspension $\left(5 \times 10^{4} / \mathrm{ml} ; 100 \mu \mathrm{l}\right)$ was inoculated into 96 -well plates, and the cells were cultured at $37^{\circ} \mathrm{C}$ in $5 \% \mathrm{CO}_{2}$ overnight. After the cells had adhered to the well, the supernatant was discarded and the PBMCs stimulated with the mixtures were added to SKOV3 cells. After $48 \mathrm{~h}$ of incubation, $20 \mu \mathrm{l}$ MTT (5 mg/ml; Sigma-Aldrich; EMD Millipore, Darmstadt, Germany) was added to each well and incubated at $37^{\circ} \mathrm{C}$ in a $5 \% \mathrm{CO}_{2}$ incubator for an additional $4 \mathrm{~h}$. The supernatant was then removed and $150 \mu$ ldimethyl sulfoxide (Sigma-Aldrich; EMD Millipore) was added to each well and the cells were gently shaken for 10 min until the crystals had dissolved. Absorbance values were determined using an ELISA reader at $490 \mathrm{~nm}$.

Establishment of CTL cultures in vitro and cell growth curves. A mixture of CpGODN (30 $\mu \mathrm{g} / \mathrm{ml})$, ginsenoside Rg1 $(30 \mu \mathrm{g} / \mathrm{ml})$ and HER2/neu antigen peptide $(10 \mu \mathrm{g} / \mathrm{ml})$, termed the specific mixture, was added to PBMCs $\left(1 \times 10^{4} / \mathrm{ml}\right)$ in 24 -well plates and cultured for 34 days at $37^{\circ} \mathrm{C}$. The medium was replaced and the cells were adjusted to $1 \times 10^{6} / \mathrm{ml}$ every 3 days. On day 34 , the cells were collected and named HER2/neu-specific CTLs. Growth curves were drawn according to cell counts on days 1 , $4,7,10,13,16,19,22,25,28,31$ and 34 . 
Karyotype analysis. Karyotypes were analyzed by conventional Giemsa staining. Conventional cytogenetic analysis of PBMCs was performed prior to and following stimulation with the specific mixture. PBMCs $\left(1 \times 10^{5}\right.$ cells/well $)$ were treated with $0.05 \mathrm{ml}$ colcemid $(25 \mu \mathrm{g} / \mathrm{ml}$; Sigma-Aldrich; EMD Millipore) for $4 \mathrm{~h}$ at $37^{\circ} \mathrm{C}$, after which the cells were harvested and resuspended in $8 \mathrm{ml} 37^{\circ} \mathrm{C}$ hypotonic solution, and then cultured at $37^{\circ} \mathrm{C}$ in a humidified $5 \% \mathrm{CO}_{2}$ incubator for $30 \mathrm{~min}$. Following incubation, cells were harvested and fixed in freshly prepared fixative (volume ratio of methanol:acetic acid, 3:1), and slides were prepared by hot-plate drying for $15 \mathrm{~min}$. Metaphase chromosomes were banded using trypsin-Giemsa and karyotyped according to the International System for Human Cytogenetic Nomenclature (ISCN 2005) (32).

Flow cytometry. PBMCs were harvested following incubation with specific mixture for 10, 20 or 30 days. The expression of cluster of differentiation (CD)3, CD4 and CD8 on the surface of PBMCs was measured using flow cytometry. Briefly, the cells were washed in fluorescence-activated cell sorting (FACS) medium [phosphate-buffered saline (PBS) containing $1 \%$ bovine serum albumin (Sigma-Aldrich; EMD Millipore)] and stained at $4^{\circ} \mathrm{C}$ for 20 min with the following antibodies: Anti-CD3-phycoerythrin (PE)-cyanine 5 (1:20; cat. no. ab157300; Abcam, Cambridge, UK), CD4-fluorescein isothiocyanate (1:20; cat. no. ab59474; Abcam) and CD8-PE (1:20; cat. no. ab210327; Abcam). Thereafter, cells were washed three times with PBS and analyzed by FACS (FCM-500; Beckman Coulter, Inc., Brea, CA, USA).

Inhibition of SKOV3 cells treated with HER2/neu-specific CTLs. PBMCs were divided into three groups, as follows: i) The effect cell control group; ii) the HER2/neu group (positive control group); and iii) the specific mixture group (experimental group). PBMCs $\left(1 \times 10^{6} / \mathrm{ml}\right)$ were seeded into 96-well plates in triplicate; each well had a volume of $100 \mu \mathrm{l}$. Subsequently, the cells were treated with $10 \mu \mathrm{g} / \mathrm{ml} \mathrm{HER} 2 / \mathrm{neu}$ or the specific mixture (30 $\mu \mathrm{g} / \mathrm{ml} \mathrm{CpGODN,} 30 \mu \mathrm{g} / \mathrm{ml}$ ginsenoside $\mathrm{Rg} 1$ and $10 \mu \mathrm{g} / \mathrm{ml} \mathrm{HER} 2 / \mathrm{neu}$ ) and cultured at $37^{\circ} \mathrm{C}$ in a $5 \% \mathrm{CO}_{2}$ incubator. Cells collected on day 19 were used as the effect cells. SKOV3 cells in the logarithmic growth phase were digested with $0.25 \%$ trypsin and the single cell suspension was inoculated into 96 -well plates at $5 \times 10^{4} / \mathrm{ml}$. The cells were cultured at $37^{\circ} \mathrm{C}$ in $5 \% \mathrm{CO}_{2}$ overnight, after which the supernatant was discarded, such that the adherent cells became the target cells. SKOV3 cells were added to the three groups of effect cells at effect cell-to-target cell ratios of 5:1, 10:1, 20:1 and 40:1. The group with no effect cells was the target cell control group. Cells were cultured at $37^{\circ} \mathrm{C}$ in a $5 \%$ $\mathrm{CO}_{2}$ incubator for $48 \mathrm{~h}$. MTT assays were performed at 6,12 , 18, 24, 30, 36, 42 and $48 \mathrm{~h}$, and absorbance values were determined using an ELISA reader at $490 \mathrm{~nm}$. The CTL inhibition rate on SKOV3 cells was calculated as follows: CTL inhibitory rate $(\%)=\left[\right.$ target cell control group $\mathrm{A}_{490}$ - (experimental group $\mathrm{A}_{490}$ - effect cell control group $\left.\mathrm{A}_{490}\right)$ ] / target cell control group $\mathrm{A}_{490} \times 100$. The inhibitory effect of HER2/neu-specific CTLs on SKOV3 cells at different time points was tested in the following two groups: i) The experimental group treated with specific mixture at the effect-to-target ratio of 20:1; and ii) the control group added into equal medium with no effect cells.

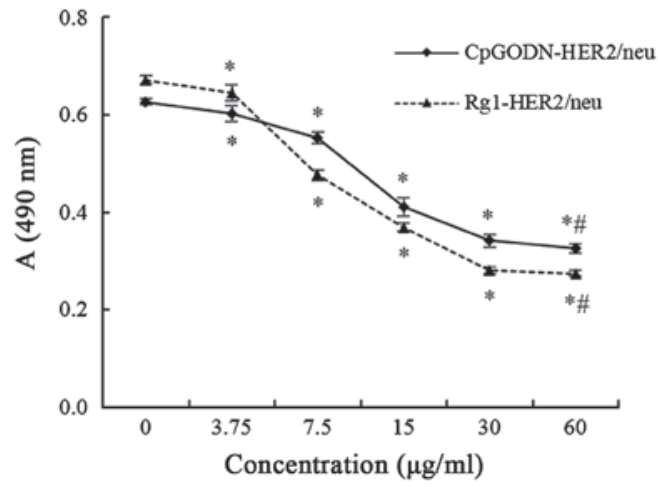

Figure 1. Effect of stimulated peripheral blood mononuclear cells (PBMCs) on SKOV3 cell viability, as assessed using MTT assays. PBMCs were stimulated for 7 days with various concentrations $(3.75,7.5,15,30$ or $60 \mu \mathrm{g} / \mathrm{ml})$ of CpGODN or ginsenoside Rg1 and HER2/neu antigen peptide. SKOV3 cells were treated with the activated PBMCs for $48 \mathrm{~h}$, after which their viability was assessed using MTT assays. Data are presented as the mean \pm standard deviation of six independent experiments. ${ }^{*} \mathrm{P}<0.05$ vs. the group without CpGODN or ginsenoside $\mathrm{Rg} 1 .{ }^{\#} \mathrm{P}>0.05$ vs. the group stimulated with $30 \mu \mathrm{g} / \mathrm{ml}$ CpGODN or ginsenoside Rg1. CpGODN, CpG oligodeoxynucleotide; HER2/neu, human epidermal growth factor receptor 2.

Statistical analysis. Data are presented as the mean \pm standard deviation. Comparisons among the groups were performed using one way analysis of variance and Tukey's test. Between group comparisons were performed using Student's t-tests. Statistical analyses were conducted using SPSS 19.0 statistical software (IBM SPSS, Armonk, NY, USA). P<0.05 was considered to indicate a statistically significant difference.

\section{Results}

Stimulation of PBMCs with various concentrations of immunological adjuvant and HER/neu antigen peptide. To observe the common effects of CpGODN and HER2/neu antigen peptide and ginsenoside $\mathrm{Rg} 1$ and HER2/neu antigen peptide stimulation on PBMC activation, MTT assays were performed to assess the viability of SKOV3 cells treated with stimulated PBMCs. As shown in Fig. 1, the number of viable SKOV3 cells was significantly decreased as the concentration of CpGODN or ginsenoside Rg1 was increased. These results suggested that increasing the number of stimulated PBMCs significantly reduced the viability of SKOV3 cells $(\mathrm{P}=0.047$, $<0.001,<0.001,<0.001$ and $<0.001$ for the $3.75,7.5,15,30$ and $60 \mu \mathrm{g} / \mathrm{ml} \mathrm{CpGODN-HER2/neu} \mathrm{groups} \mathrm{vs.} \mathrm{the} \mathrm{group} \mathrm{without}$ CpGODN, respectively; and $\mathrm{P}=0.040,<0.001,<0.001,<0.001$ and $<0.001$ for the $3.75,7.5,15,30$ and $60 \mu \mathrm{g} / \mathrm{ml}$ vs. the group without $\mathrm{Rg} 1$, respectively). However, the viability of SKOV3 cells stimulated with $60 \mu \mathrm{g} / \mathrm{ml}$ CpGODN or ginsenoside Rg1 was not significantly different compared with those stimulated with $30 \mu \mathrm{g} / \mathrm{ml} \mathrm{CpGODN}$ or ginsenoside $\mathrm{Rg} 1(\mathrm{P}=0.688$ for the CpGODN-HER2/neu group and $\mathrm{P}=0.953$ for the Rg1-HER2/ neu group). Therefore, $30 \mu \mathrm{g} / \mathrm{ml} \mathrm{CpGODN}$ and ginsenoside Rg1 were used for subsequent experiments.

Karyotype analysis of HER2/neu-specific CTLs. To assess the safety of the specific CTL culture system in vitro, the PBMC karyotype was analyzed in order to detect whether PBMCs were stable following stimulation with the specific mixture. As 
A

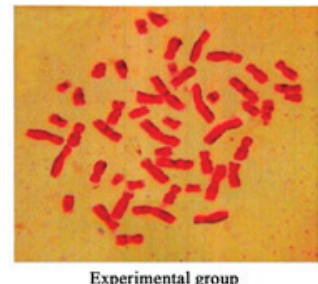

Experimental group

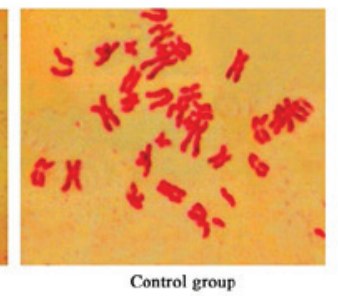

B

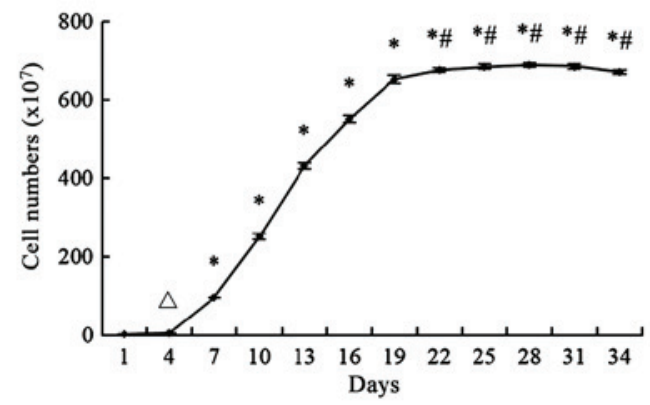

C

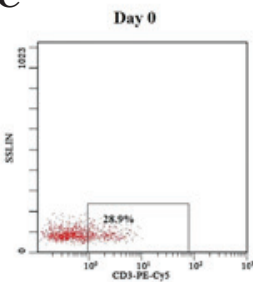

Day 10

Day 20
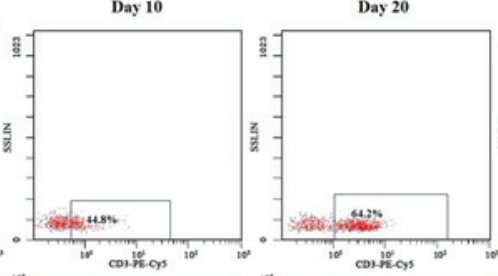

Day 30

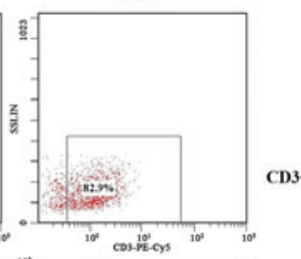

D
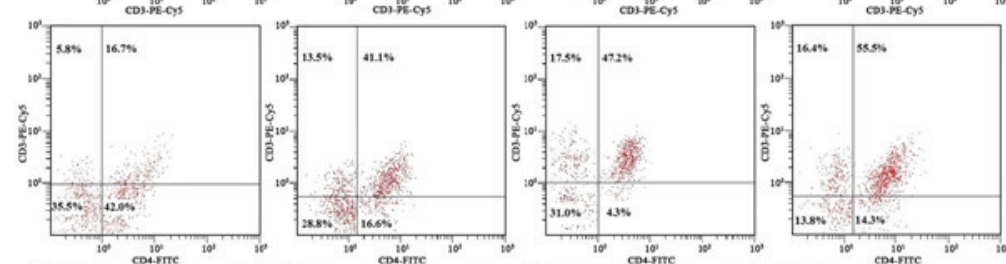

CD3+
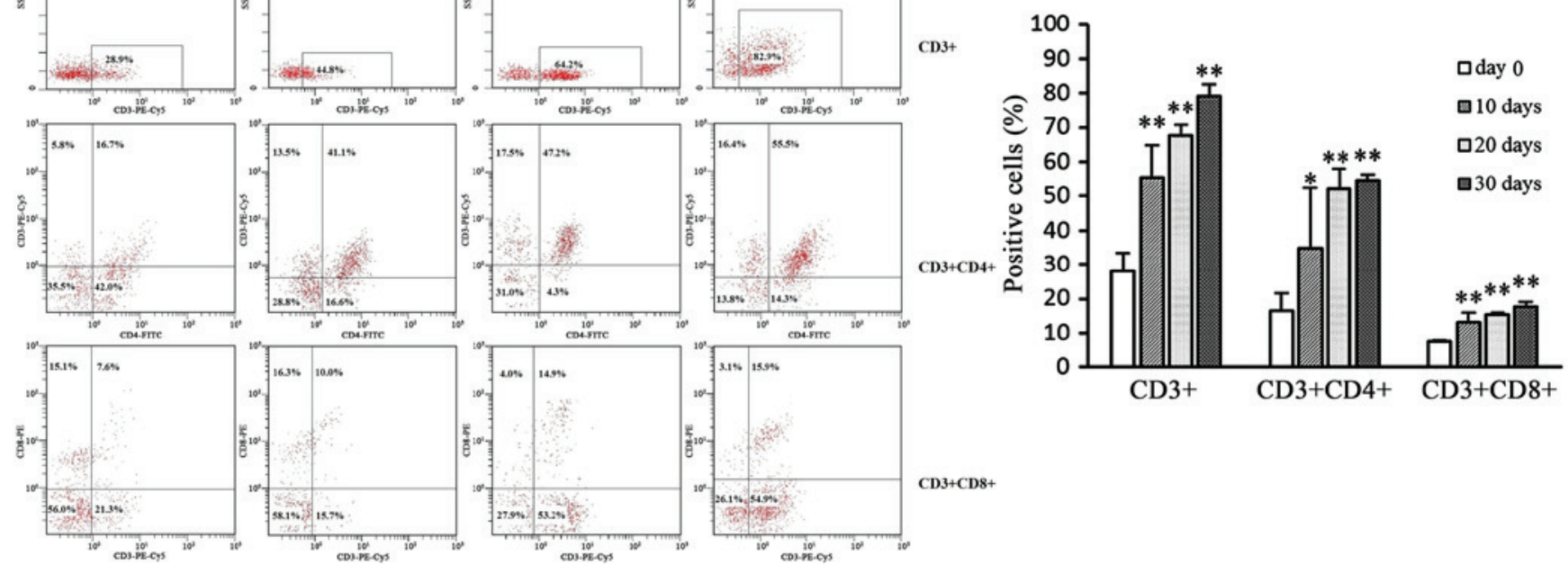

CD3+

CD3+CD4+ CD3+CD8+

Figure 2. Characterization of the specific cytotoxic T lymphocyte (CTL) culture system in vitro. (A) Karyotype analysis of peripheral blood mononuclear cells (PBMCs) was performed using conventional Giemsa staining. (a) The karyotype of PBMCs following stimulation with specific mixture (the experimental group). (b) The karyotype of PBMCs without stimulation (the control group). (B) Cell proliferation was determined by counting total cell numbers at 1, 4, 7, $10,13,16,19,22,25,28,31$ and 34 days of culture. Values are the mean \pm standard deviation $(\mathrm{SD})$ of three independent experiments. ${ }^{*} \mathrm{P}<0.01,{ }^{\Delta} \mathrm{P}>0.05 \mathrm{vs}$. the cell number on day $1 .{ }^{~} \mathrm{P}>0.05$ vs. the cell number on day 19 . (C and D) The percentages of $\mathrm{CD}^{+}, \mathrm{CD}^{+} \mathrm{CD} 4^{+}$and $\mathrm{CD} 3^{+} \mathrm{CD} 8^{+} \mathrm{PBMCs}$ were assayed by flow cytometry prior to stimulation and on days 10,20 and 30 following stimulation with the specific mixture. Values are the mean \pm SD of three independent experiments. "P $<0.05,{ }^{* *} \mathrm{P}<0.01$ vs. day $0 . \mathrm{CD}$, cluster of differentiation; PE-Cy5, phycoerythrin-cyanine 5; FITC, fluorescein isothiocyanate.

shown in Fig. 2A, there was no change in the PBMC karyotype following stimulation with the specific mixture.

Proliferation of specific mixture-treated PBMCs. The number of PBMCs was counted on days 1, 4, 7, 10, 13, 16, 19, 22, 25, 28 , 31 and 34 , in order to detect the effect of the specific mixture on the growth of PBMCs. As shown in Fig. 2B, the number of cells increased as the culture time was extended. Cell proliferation was not detected prior to day 4 ( $\mathrm{P}=1.000$ for 4 th day group vs. 1st day group). However, the number of PBMCs was significantly increased after day 7 ( $\mathrm{P}<0.01$ for groups on days $7,10,13$, $16,19,22,25,28,31$ and 34 vs. 1st day group), although there was no significant difference in the cell number after day 19 $(\mathrm{P}=0.986,0.230,0.094,0.195$ and 1.000 for groups on days 22 , $25,28,31$ and 34 vs. 19th day group). Therefore, the stimulated cells collected on day 19 were used as the effector cells in the subsequent experiments.

Immunophenotype of PBMCs. T-cells are characterized by the $\mathrm{CD}^{+}$molecular phenotype. CTLs are $\mathrm{CD}^{+}{ }^{+} \mathrm{T}$-cells, while $\mathrm{CD} 4^{+} \mathrm{T}$-cells constitutes another molecular phenotype $(33,34)$. To identify whether the stimulated PBMCs were CTLs, flow cytometry was performed to examine the immunophenotype. As shown in Fig. 2C and D, the immunophenotypes of PBMCs were changed following stimulation with the specific mixture. The proportion of cells that expressed CD3 increased from $28.17 \pm 5.14$ to $79.30 \pm 3.17 \%$ following stimulation $(\mathrm{P}<0.01$ for 30th day group vs. group on day 0). Furthermore, the cells expressing both CD3 and CD4 increased from 16.40 \pm 5.16 to $54.53 \pm 1.85 \%$ after 30 days of stimulation $(\mathrm{P}=0.002$ for 30 th day group vs. group on day 0 ), and the number of cells expressing CD3 and CD8 were significantly increased $(\mathrm{P}<0.01$ for 30th day group vs. group on day 0 ). These results suggested that specific CTL cells had been successfully induced by the specific mixture.

Lethal and inhibitory effects of HER2/neu-specific CTLs on SKOV3 cells. Following the establishment and identification of the specific CTL system, the lethal and inhibitory effects of the HER2/neu-specific CTLs on SKOV3 ovarian cancer cells was assessed using MTT assays. As shown in Fig. 3A, as compared with the positive control group, the experimental group appeared to have a stronger lethal effect on SKOV3 cells, which increased as the ratio of effect cells-to-target cells was 

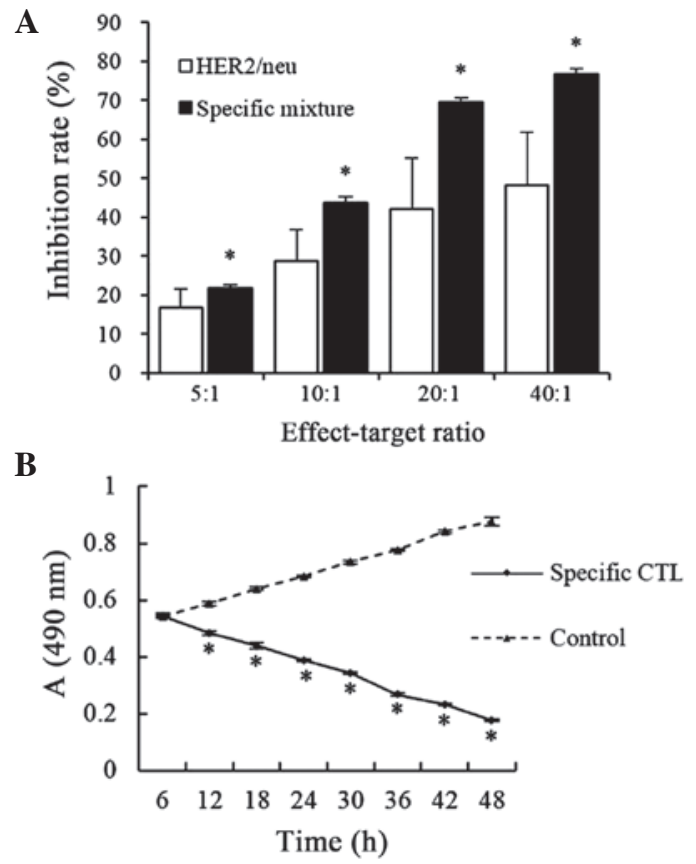

Figure 3. Inhibitory effect of HER2/neu-specific CTLs on SKOV3 cells. (A) SKOV3 cells were treated with HER2/neu-specific CTLs at different effect-to-target cell ratios (5:1, 10:1, 20:1 or 40:1), and the inhibitory effect was analyzed using MTT assays. Inhibition rates were calculated according to the formula: Inhibitory rate $(\%)=$ [target cell control group $\mathrm{A}_{490}$ - (experimental group $\mathrm{A}_{490}$ - effect cell control group $\mathrm{A}_{490}$ )] / target cell control group x 100 Values are the mean \pm standard deviation (SD) of six independent experiments. ${ }^{*} \mathrm{P}<0.05$ vs. the positive control group (HER $2 /$ neu). (B) SKOV3 cells were treated with HER2/neu-specific CTLs at the effect-to-target cell ratio of 20:1, and analyzed using MTT assays after 6, 12, 18, 24, 30, 36, 42 anc $48 \mathrm{~h}$ of treatment. Values are the mean $\pm \mathrm{SD}$ of six independent experiments. ${ }^{*} \mathrm{P}<0.01$ vs. the control group. CTL, cytotoxic T lymphocytes; HER2/neu, human epidermal growth factor receptor 2.

increased $(\mathrm{P}=0.049,0.034,0.023$ and 0.022 for experimental groups with effect-target ratio of 5:1, 10:1, 20:1 and 40:1 vs. positive control groups, respectively). These results suggested that the HER2/neu-specific CTLs exerted lethal effects on ovarian cancer cells, which were positively related to the number of activated PBMCs. Therefore, the effect-to-target ratio of 20:1 was used in the subsequent experiments.

The inhibitory effect of the effect-to-target ratio of 20:1 on SKOV3 cells is shown in Fig. 3B. The growth curve of SKOV3 cells treated with the control group PBMCs (without HER2/neu, CpGODN and ginsenoside Rg1) showed an increasing trend during the first $48 \mathrm{~h}$. Conversely, the growth curve of the experimental group treated with HER2/neuspecific CTLs showed a decreasing trend during the first $48 \mathrm{~h}$. The number of SKOV3 cells in the experimental group was significantly decreased compared with the control group at the same time point $(\mathrm{P}<0.01$ for experimental groups at $12,18,24$, $30,36,42$ and $48 \mathrm{~h}$ vs. the corresponding control groups).

\section{Discussion}

Ovarian cancer is the most lethal gynecological malignancy. Primary treatment involves surgical debulking of the visible disease, followed by adjuvant chemotherapy (7). However, even though $>70 \%$ of patients initially respond to cisplatin, the prognosis is still poor, due to chemoresistance or high proportion of advance-stage cases (4). Currently, tumor biological therapies are receiving increasing attention as an alternative effective therapeutic strategy to operation, radiotherapy and chemotherapy.

As a novel adjuvant treatment method, immunotherapy has been shown to improve the antitumor immune response in the body, so as to eliminate residual metastatic lesions and delay the development of cancer following the standard cytoreductive surgery and platinum-based chemotherapy (35). In addition, immunotherapy was reported to effectively improve patients' autonomic anticancer immunity, strengthen their physique, reduce chemotherapy resistance, enhance the effect of chemotherapy on ovarian cancer and extend the valid period of survival (10). Antigen-specific active immunotherapy aims to induce tumor-antigen-specific antitumor immune responses, and has emerged as an alternative treatment for ovarian cancer (36). In the process of an immune response, tumor antigens are processed by APCs and presented to CTLs (14). Adjuvants are able to non-specifically alter or enhance the body's immune response to specific antigens, and enhance the immunogenicity of the corresponding antigen or change the type of immune response (37).

In the present study, HER 2/neu was used as the tumor antigen adjuvant to enhance the immunogenicity of HER $2 /$ neu and the specificity of the immune response. The HER2/neu antigen peptide was combined with CpGODN and ginsenoside $\mathrm{Rg} 1$, and the mixture was used to stimulate $\mathrm{T}$ lymphocytes in peripheral blood via the double-signal pathway. Subsequently, CTLs were efficiently proliferated in vitro. By controlling a single variable, the optimum ratio of CpGODN, ginsenoside Rg1 and HER2/neu antigen peptide was found. MTT assays demonstrated that, when the concentration of CpGODN and ginsenoside Rg1 was $30 \mu \mathrm{g} / \mathrm{ml}$, and that of HER $2 /$ neu was $10 \mu \mathrm{g} / \mathrm{ml}$, the lethal effect of specific CTL on SKOV3 cells was the most potent. Therefore, a specific CTL in vitro culture system was established. Following treatment with the specific mixture, PBMCs underwent a 4-day adaptive phase, followed by proliferation; the logarithmic growth phase was reached on day 7. From day 19, the growth of cells began to plateau, although PBMCs were shown to remain viable up until day 34. As a result of active metabolism in the logarithmic phase, the cell condition was fine. Therefore, the cells harvested on day 19 were used as effector cells in the subsequent experiments to ensure both a good condition and quantity of cells. Flow cytometry was used to asses the immunophenotypes of the PBMCs. The results indicated that, following treatment with the specific mixture, the percentages of $\mathrm{CD}^{+}, \mathrm{CD}^{+} \mathrm{CD}^{+}$and $\mathrm{CD} 3^{+} \mathrm{CD}^{+}{ }^{+} \mathrm{PBMCs}$ were significantly increased compared with the control group, which demonstrated that a large quantity of CTL cells were induced successfully. Through chromosome karyotype analyses, it was shown that the lymphocyte karyotype did not change following stimulation with the specific mixture. These results suggested that HER2/neu-specific CTLs may be safely reinfused into the human body. The high survival rate and strong proliferative capacity of the HER2/neu-specific CTLs were the basis for their strong cytotoxic activity, thereby solving the lack of effector cells obtained by amplification in vitro (38).

The rapid proliferation of cells is one of the most important characteristics of malignant tumors. Therefore, effectively 
inhibiting the growth and proliferation of tumor cells is one of the main purposes of antitumor therapies. In the present study, the MTT method (39) was adopted to investigate the inhibitory effect of HER2/neu-specific CTLs on SKOV3 cells at different effect cell-to-target cell ratios. HER2/neu-specific CTLs were diluted into various concentrations according to the different effect-to-target cell ratios and added to SKOV3 cells. The results showed that, compared with the control group, the inhibitory effect on SKOV3 cells was significantly increased for all experimental groups. The inhibition rate was $76.75 \%$ when the effect-to-target cell ratio was $40: 1$. The influence of HER2/neu-specific CTLs on SKOV3 cell viability was assessed using the MTT method, and growth curves for SKOV3 cells in the control group and experimental groups were constructed. The result indicated that, compared with the control group, the growth of SKOV3 cells treated with HER2/ neu-specific CTLs was significantly inhibited. These results suggested that HER2/neu-specific CTLs were effective across the entire growth processes of SKOV3 cells.

In conclusion, the present study united CpGODN and ginsenoside $\mathrm{Rg} 1$ as an immune adjuvant, which, combined with the HER2/neu antigen peptide, was used to rapidly induce a large number of PBMCs to form CTL cells, thereby establishing a large-scale specific CTL culture system in vitro. This system was shown to satisfy the safety of clinical reinfusion. The high rate of proliferation of the HER2/neu-specific CTLs solved the problem of obtaining sufficient effector cells by amplification in vitro. In addition, the present study demonstrated the high antigen specificity of the specific CTL in vitro, which had significant inhibitory and lethal effects on ovarian cancer cells. The results of the present study may serve as an experimental foundation for the systematic analysis of the function and mechanisms of HER2/neu-specific CTLs in tumor immunotherapy.

\section{Acknowledgements}

This study was supported by grants from the National Natural Science Foundation of China (grant nos. 81302242 and 81272875), the Ministry of Education for Young Teacher Foundation of China (grant no. 20110061120084), the Jilin province Science and Technology Funds (grant nos. 20120957, 20130102094JC and 20140204022YY), and the Jilin province Development and Reform Commission Funds (grant no. 2013C026-3).

\section{References}

1. Jemal A, Siegel R, Xu J and Ward E: Cancer statistics, 2010. CA Cancer J Clin 60: 277-300, 2010.

2. Bell DA: Origins and molecular pathology of ovarian cancer. Mod Pathol 18 (Suppl 2): S19-S32, 2005.

3. Lu KH, Skates S, Hernandez MA, Bedi D, Bevers T, Leeds L, Moore R, Granai C, Harris S, Newland W, et al: A 2-stage ovarian cancer screening strategy using the Risk of Ovarian Cancer Algorithm (ROCA) identifies early-stage incident cancers and demonstrates high positive predictive value. Cancer 119 3454-3461, 2013.

4. Cai Y, Tan X, Liu J, Shen Y, Wu D, Ren M, Huang P and Yu D: Inhibition of $\mathrm{PI} 3 \mathrm{~K} / \mathrm{Akt} / \mathrm{mTOR}$ signaling pathway enhances the sensitivity of the SKOV3/DDP ovarian cancer cell line to cisplatin in vitro. Chin J Cancer Res 26: 564-572, 2014.

5. Lenhard SM, Bufe A, Kümper C, Stieber P, Mayr D, Hertlein L, Kirschenhofer A, Friese K and Burges A: Relapse and survival in early-stage ovarian cancer. Arch Gynecol Obstet 280: 71-77, 2009.
6. Mantia-Smaldone GM, Corr B and Chu CS: Immunotherapy in ovarian cancer. Hum Vaccin Immunother 8: 1179-1191, 2012.

7. Adams SF, Levine DA, Cadungog MG, Hammond R, Facciabene A, Olvera N, Rubin SC, Boyd J, Gimotty PA and Coukos G: Intraepithelial T cells and tumor proliferation: Impact on the benefit from surgical cytoreduction in advanced serous ovarian cancer. Cancer 115: 2891-2902, 2009.

8. Zhang L, Conejo-Garcia JR, Katsaros D, Gimotty PA, Massobrio M, Regnani G, Makrigiannakis A, Gray H, Schlienger K, Liebman MN, et al: Intratumoral $\mathrm{T}$ cells, recurrence and survival in epithelial ovarian cancer. N Engl J Med 348: 203-213, 2003.

9. Rosenberg SA, Restifo NP, Yang JC, Morgan RA and Dudley ME: Adoptive cell transfer: A clinical path to effective cancer immunotherapy. Nat Rev Cancer 8: 299-308, 2008.

10. Berek J, Taylor P, McGuire W, Smith LM, Schultes B and Nicodemus CF: Oregovomab maintenance monoimmunotherapy does not improve outcomes in advanced ovarian cancer. J Clin Oncol 27: 418-425, 2009.

11. Dadmarz RD, Ordoubadi A, Mixon A, Thompson CO, Barracchini KC, Hijazi YM, Steller MA, Rosenberg SA and Schwartzentruber DJ: Tumor-infiltrating lymphocytes from human ovarian cancer patients recognize autologous tumor in an MHC class II-restricted fashion. Cancer J Sci Am 2: 263-272, 1996.

12. Santin AD, Bellone S, Ravaggi A, Pecorelli S, Cannon MJ and Parham GP: Induction of ovarian tumor-specific CD8+ cytotoxic T lymphocytes by acid-eluted peptide-pulsed autologous dendritic cells. Obstet Gynecol 96: 422-430, 2000.

13. Smith KA: Interleukin-2: Inception, impact, and implications. Science 240: 1169-1176, 1988.

14. Gri G, Gallo E, Di Carlo E, Musiani P and Colombo MP: OX40 ligand-transduced tumor cell vaccine synergizes with GM-CSF and requires CD40-Apc signaling to boost the host $\mathrm{T}$ cell antitumor response. J Immunol 170: 99-106, 2003.

15. Coumes F, Huang CY, Huang CH, Coudane J, Domurado D, Li S, Darcos V and Huang MH: Design and development of immunomodulatory antigen delivery systems based on peptide/PEG-PLA conjugate for tuning immunity. Biomacromolecules 16: 3666-3673, 2015

16. Preston CC, Goode EL, Hartmann LC, Kalli KR and Knutson KL: Immunity and immune suppression in human ovarian cancer. Immunotherapy 3: 539-556, 2011.

17. Meden $\mathrm{H}$ and Kuhn W: Overexpression of the oncogene c-erbB-2 (HER2/neu) in ovarian cancer: A new prognostic factor. Eur J Obstet Gynecol Reprod Biol 71: 173-179, 1997.

18. Wang SC and Hung MC: HER2 overexpression and cancer targeting. Semin Oncol 28: 115-24, 2001.

19. Tuefferd M, Couturier J, Penault-Llorca F, Vincent-Salomon A, Broët P, Guastalla JP, Allouache D, Combe M, Weber B, Pujade-Lauraine E and Camilleri-Broët S: HER2 status in ovarian carcinomas: A multicenter GINECO study of 320 patients. PLoS One 2: e1138, 2007.

20. Høgdall EV, Christensen L, Kjaer SK, Blaakaer J, Bock JE, Glud E, Nørgaard-Pedersen B and Høgdall CK: Distribution of HER-2 overexpression in ovarian carcinoma tissue and its prognostic value in patients with ovarian carcinoma: From the Danish MALOVA ovarian cancer study. Cancer 98: 66-73, 2003.

21. Teplinsky E and Muggia F: Targeting HER2 in ovarian and uterine cancers: Challenges and future directions. Gynecol Oncol 135: 364-370, 2014

22. Klinman DM, Klaschik S, Sato T and Tross D: CpG oligonucleotides as adjuvants for vaccines targeting infectious diseases. Adv Drug Deliv Rev 61: 248-255, 2009.

23. Xia Y, Gupta GK, Castano AP, Mroz P, Avci P and Hamblin MR: $\mathrm{CpG}$ oligodeoxynucleotide as immune adjuvant enhances photodynamic therapy response in murine metastatic breast cancer. J Biophotonics 7: 897-905, 2014.

24. Qi LW, Wang CZ and Yuan CS: American ginseng: Potential structure-function relationship in cancer chemoprevention. Biochem Pharmacol 80: 947-954, 2010.

25. Lee EJ, Ko E, Lee J, Rho S, Ko S, Shin MK, Min BI, Hong MC, Kim SY and Bae H: Ginsenoside Rg1 enhances CD4(+) T-cell activities and modulates Th1/Th2 differentiation. Int Immunopharmacol 4: 235-244, 2004.

26. Su F, Yuan L, Zhang L and Hu S: Ginsenosides Rg1 and Re act as adjuvant via TLR4 signaling pathway. Vaccine 30: 4106-4112, 2012.

27. Posevitz-Fejfár A, Posevitz V, Gross CC, Bhatia U, Kurth F, Schütte V, Bar-Or A, Meuth SG and Wiendl H: Effects of blood transportation on human peripheral mononuclear cell yield, phenotype and function: Implications for immune cell biobanking. PLoS One 9: e115920, 2014. 
28. Weidanz JA, Nguyen T, Woodburn T, Neethling FA, Chiriva-Internati M, Hildebrand WH and Lustgarten J: Levels of specific peptide-HLA class I complex predicts tumor cell susceptibility to CTL killing. J Immunol 177: 5088-5097, 2006.

29. Conrad H, Gebhard K, Krönig H, Neudorfer J, Busch DH, Peschel $\mathrm{C}$ and Bernhard H: CTLs directed against HER2 specifically cross-react with HER3 and HER4. J Immunol 180: 8135-8145, 2008

30. Mittendorf EA, Holmes JP, Ponniah S and Peoples GE: The E75 HER2/neu peptide vaccine. Cancer Immunol Immunother 57: 1511-1521, 2008.

31. Vertuani S, Triulzi C, Roos AK, Charo J, Norell H, Lemonnier F, Pisa P, Seliger B and Kiessling R: HER-2/neu mediated down-regulation of MHC class I antigen processing prevents CTL-mediated tumor recognition upon DNA vaccination in HLA-A2 transgenic mice. Cancer Immunol Immunother 58: 653-664, 2009.

32. Shaffer LG and Tommerup N (eds): An international system for human cytogenetic nomenclature (2005). S Karger AG, Basel, 2005.

33. Stuge TB, Holmes SP, Saharan S, Tuettenberg A, Roederer M, Weber JS and Lee PP: Diversity and recognition efficiency of T cell responses to cancer. PLoS Med 1: e28, 2004.
34. Yee C, Gilbert MJ, Riddell SR, Brichard VG, Fefer A, Thompson JA, Boon T and Greenberg PD: Isolation of tyrosinase-specific CD8+ and CD4+ T cell clones from the peripheral blood of melanoma patients following in vitro stimulation with recombinant vaccinia virus. J Immunol 157: 4079-4086, 1996.

35. Zsiros E, Tanyi J, Balint K and Kandalaft LE: Immunotherapy for ovarian cancer: Recent advances and perspectives. Curr Opin Oncol 26: 492-500, 2014

36. Leffers N, Daemen T, Helfrich W, Boezen HM, Cohlen BJ, Melief CJ and Nijman HW: Antigen-specific active immunotherapy for ovarian cancer. Cochrane Database Syst Rev 9: CD007287, 2014

37. Powell BS, Andrianov AK and Fusco PC: Polyionic vaccine adjuvants: Another look at aluminum salts and polyelectrolytes. Clin Exp Vaccine Res 4: 23-45, 2015.

38. Sachamitr P, Hackett S and Fairchild PJ: Induced pluripotent stem cells: Challenges and opportunities for cancer immunotherapy. Front Immunol 5: 176, 2014.

39. Montoro E, Lemus D, Echemendia M, Martin A, Portaels F and Palomino JC: Comparative evaluation of the nitrate reduction assay, the MTT test, and the resazurin microtitre assay for drug susceptibility testing of clinicalisolates of Mycobacterium tuberculosis. J Antimicrob Chemother 55: 500-505, 2005. 